\title{
Functional Outcome of Intracapsular Femoral Neck Fractures Treated by Bipolar Hemiarthroplasty
}

\author{
ZAMIR HUSSAIN TUNIO', RIZWAN ALI JHATIYAL², MUHAMMAD AZEEM AKHUND ${ }^{3}$, MUHAMMAD KASHIF ABBASI ${ }^{4}$, \\ LACHMAN DAS MAHESHWARI ${ }^{5}$, ABDUL RAUF MEMON6 \\ ${ }^{1}$ Assistant Professor, ${ }^{5}$ Senior Registrar, Department of Orthopaedic Surgery and Traumatology, Liaquat University of Medical \& Health \\ Sciences, Jasmshoro \\ ${ }^{2}$ Consultant Orthopaedic Surgeon, Liaquat University Hospital, Hyderabad \\ ${ }^{3}$ Associate Professor, Department of Orthopedic Surgery \& Traumatology, Peoples University of Medical \& Health Sciences Shaheed \\ Benazir Abad \\ ${ }^{4}$ Assistan Professor of Orthopedic Surgery and Traumatology, Pir Abdul Qadir Shah Jilani Institute of Medical Sciences, Gambat \\ ${ }^{6}$ Assistant Professor, Department of Neurosurgery, Liaquat University of Medical \& Health Sciences, Jasmshoro \\ Correspondence to Dr. Rizwan Ali Jhatiyal E-mai: rizwan.jhatiyal@gmail.com Cell 0344-3241365
}

\begin{abstract}
Aim: To evaluate the functional outcome of bipolar hemiarthroplasty in intracapsular fracture neck of femur.

Study design: Descriptive cross sectional study.

Place and duration of study: Department of Orthopaedic Surgery \& Traumatology, Peoples Medical University

Hospital, Shaheed Benazir Abad from $1^{\text {st }}$ December 2017 to $31^{\text {st }}$ December 2020.

Methodology: Sixty six cases of intracapsular femoral neck fractures with age ranging from 50 year to 75 year of either gender who were ambulatory before injury were included; while basicervical, younger than 50 years, with neuromuscular disorder, unfit for surgery, open fracture, bilateral injuries, osteoarthritis of hip, Rheumatoid, Gouty, pathological fractures, bedridden \& who did not give consent for study, were excluded from the study. Functional outcome assessed by Harris hip score \& data analyzed by SPSS version 23.

Results: Twenty six $(59.09 \%)$ were male and $40(40.91 \%)$ were female with mean age of $64.3 \pm 7.77$ year. Average time from injury to hospital arrival was $14.7 \pm 6.8$ hours. Average time from hospitalization to surgery was $4.67 \pm 2.23$ days. Average time of surgery was $55.67 \pm 9.9$ minutes. Average hospital stay was $9.7 \pm 4.3$ days. The average time of follow-up was $18.45 \pm 7.63$ months.

Conclusion: Bipolar implant is safe, effective, reliable, stable and cost effective implant for intracpsular fracture of femoral neck in elderly populace. The $66.66 \%$ of patients have satisfactory Harris hip score in follow up duration of $18.45 \pm 7.63$ months.

Keywords: Functional, Outcome, Femoral neck fractures, FNF, Bipolar, Hemiarthroplasty, HHS
\end{abstract}

\section{INTRODUCTION}

Hip fracture is a significant and crippling condition in more aged individuals, especially in ladies. The epidemiological information changes between nations, yet it is worldwide assessed that this injury will influence around $18 \%$ of ladies and $6 \%$ of men. In this way, the worldwide number of hip fracture is expected to increment from 1.26 million to 4.5 million yearly continuously $1990-2050^{1}$. The risk of femoral neck fracture [FNF] is about $40-50 \%$ in females and $13-$ $22 \%$ in males $^{2}$. These record for a fourth of all fractures in patients matured 75 years and over $^{3}$. Intra capsular femoral neck fractures count for about half of hip fractures ${ }^{4}$ and it is $6.9 \%$ in patients above 65 year. ${ }^{5}$ Intra-capsular fractures are about $60 \%$ of hip trauma, among these $80 \%$ are displaced ${ }^{6}$. These expands the danger of interruption to the femoral head blood supply, as, is related with increased risk of AVN of femoral head, nonunion, mal-union and failure to achieve anatomic reduction 7 .

The WHO in South-East Asia utilizes an age cutoff of over 60 years is geriatric population ${ }^{8}$. SPEED $\mathrm{K}$ labelled this fracture the unsolved fracture because of its no healing potential with conservative methods of bed rest \& casting. $^{9}$ Extra capsular FNF are treated well by osteosynthesis.

Received on 13-01-2021

Accepted on 28-04-2021
There is never-ending consensus on management of intra capsular fractures in osteosynthesis and arthroplasty and has remained controversial for last 5-6 decades ${ }^{10,11}$. More complications and reoperations occur after osteosynthesis in comparison with arthroplasty, however there is no agreement with respect to which treatment gives the best practical outcomes ${ }^{12}$. Regardless of the apparent straightforwardness of the hip hemiarthroplasty method, there are various varieties to the procedure; these incorporate the surgical approach ${ }^{13}$, the kind of prosthesis head $^{14}$, the strategy for stem inclusion ${ }^{15}$, and the sort of prosthesis assembly ${ }^{16}$. The ideal determination for every one of these components stays to be resolved ${ }^{17}$.

Literature does not recommend bipolar over unipolar implant. There are lot of studies done but there is no consensus bout superiority of implant. From the current evidence, no doubt, while unipolar can be related with expanded paces of acetabular erosion at present moment follow up to 1 year, there is no critical difference between the two prosthesis types for careful result, confusion profile, useful result and acetabular erosion rates at longer-term follow-up of 2 to 4 years ${ }^{14,18}$.

The current data propose that while uncemented hemi-arthoplasties can take into account a more limited especially peri-prosthetic femoral fractures; furthermore, improved post-operative outcomes as far as lingering, thigh pain and loosening of implant. Likewise, there is no critical 
distinction between the two procedures for blood loss, surgical time, cemented hemi-arthroplasties are related with lower paces of prosthesis-related problems and mortality in 1 year follow up ${ }^{15,17,18}$.

In country like Pakistan unipolar implant is widely used as a treatment option in femoral neck fractures. This study is planned to know about functional outcome of bipolar hemiarthroplasty in intracapsular fracture neck of femur [FNF] and related complications in our community.

\section{MATERIALS AND METHODS}

This descriptive, cross sectional study was conducted at Department of Orthopaedic Surgery \& Traumatology, Peoples Medical University Hospital Shaheed Benazir Abad from $1^{\text {st }}$ December 2017 to $31^{\text {st }}$ December 2020. 66 cases of intracapsular femoral neck fractures [FNF] with age ranging from 50 year to 75 year of either gender who were ambulatory before injury were included; while basicervical, younger than 50 years, with neuromuscular disorder, unfit for surgery, open fracture, bilateral injuries, osteoarthritis of hip, rheumatoid, gouty, pathological fractures, bedridden and who did not give consent for study, were excluded from the study. All patients advised for routine baseline investigations, Radiographs like X-rays pelvis with hips lateral view and of chest was advised. Physician, cardiologist and anaesthetist' opinion taken before going surgery and blood was arranged according to expectation of blood loss. If any associated comorbid was dealt accordingly. Surgery was done by orthopaedic surgeon with more than 2 year of experience at least (Fig.1). In operation theatre every effort taken to minimize the risk of postoperative complications as infection, dislocation etc.cemented bipolar arthroplasty was performed through standard technique. Postoperatively all cases were asked to mobilize and to bear weight as tolerable and assistance from physiotherapist taken to mobilize carefully. Intravenous antimicrobials continued for 2-3days. Cases were instructed to avoid movements that could dislocate the prosthesis. Then patient discharged from ward on clinical grounds and called for follow-up in outpatient department weekly for initial four weeks then fortnightly for 3 months then monthly. In each visit patient assessed clinically for any complication and Hips assessed functionally by Hip Harris Score ${ }^{19}$ and graded as excellent, good, fair and poor. Each variable noted on predesigned pro-forma. Follow-up time was measured .The data was entered and analyzed through SPSS-23.

Fig. 1: Dislocation of prosthesis with fracture of posterior wall of acetabulum

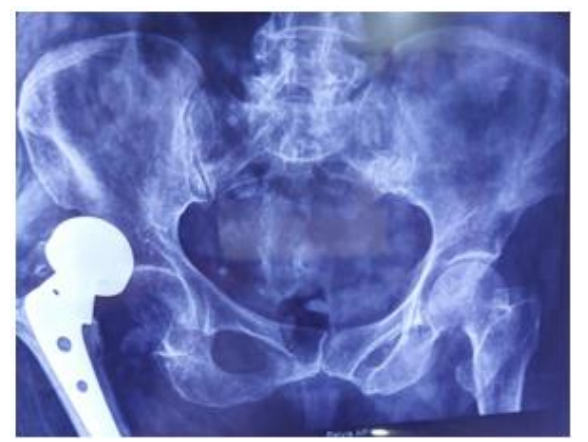

\section{RESULTS}

There were $26(59.09 \%)$ were males and $40(40.91 \%)$ were female with minimum age of 52 years and maximum of 70 years and having mean age of $64.3 \pm 7.77$ years (Table 1 ). Regarding the mode of injury, low energy trauma domestic falls was highest reported in $47(65.9 \%)$ patients, and road traffic accident in $19(34.1 \%)$ cases. $38(56.81 \%)$ cases having left sided while $28(43.19 \%)$ having right sided injury. Average time from injury to hospital arrival was $14.7 \pm 6.8$ hours. Average time from hospitalization to surgery was $4.67 \pm 2.23$ days. Average time of surgery was $55.67 \pm 9.9$ minutes. Average hospital stay was $9.7 \pm 4.3$ days.

Regarding complications; Superficial surgical site infection developed in 4, that dealt according to standards of infection management by drainage debridement deep culture and then culture specific antimicrobials, all wounds healed with proper wound care and management and none of the case complicated to deep infection. $4.54 \%$ cases had presented with dislocation during follow-up; all cases successfully reduced by close method under anaesthesia (Table 2). One lady long with dislocation presented with fracture of post wall of acetabulum, she was known case of diabetes, asthma, hypertension, ischemic heart disease, was declared as high risk candidate for surgery by all departments, so she refused for revision surgery (Fig. 2). $3.03 \%$ cases presented with periprosthetic fracture Vancouver $\mathrm{B}$ and $\mathrm{C}$ after having domestic fall that were managed with plating. $3.03 \%$ cases had acetabulum erosion and developed secondary osteoarthritis; they were managed by analgesics and physiotherapy. The average time of follow-up was $18.45 \pm 7.63$ months. Harris Hip Score at final visit of follow up was Excellent (90-100) in 19(28.78\%), Good (80-89) 25(37.87\%), Fair (70-80) $15(22.72 \%)$ \& Poor in (<70) 7(10.6\%) (Table 3).

Table 1: Demographic information of the patients $(n=66)$

\begin{tabular}{|l|c|c|}
\hline Variable & No. & $\%$ \\
\hline Gender & 26 & 39.4 \\
\hline Male & 40 & 60.6 \\
\hline Female & $64.3 \pm 7.7$ \\
\hline Age (years) & 28 & 42.42 \\
\hline Side & 38 & 57.58 \\
\hline Right & 15 & 22.72 \\
\hline Left & 51 & 77.28 \\
\hline FNF & $14.7 \pm 6.8$ \\
\hline Subcapital & $55.67 \pm 9.9$ \\
\hline Midcervical & $10 \pm 4.7$ \\
\hline Average time from injury to hospital arrival (hrs) & \multicolumn{3}{|c|}{$18.45 \pm 7.63$} \\
\hline Average surgery time (minutes) & \multicolumn{3}{|c|}{} \\
\hline Average hospital stay (days) &
\end{tabular}

Table 2: Frequency of complications $(n=66)$

\begin{tabular}{|l|c|c|}
\hline Complication & No. & $\%$ \\
\hline Superficial surgical site infection & 4 & 6.81 \\
\hline Dislocation & 3 & 4.54 \\
\hline Periprosthetic fracture & 2 & 3.03 \\
\hline Osteoarthritis & 2 & 3.03 \\
\hline
\end{tabular}

Table 3: Harris Hip Score $(n=66)$

\begin{tabular}{|l|c|c|}
\hline Harris Hip Score & No. & $\%$ \\
\hline Excellent $(90-100)$ & 19 & 28.78 \\
\hline Good $(80-89)$ & 25 & 37.87 \\
\hline Fair $(70-80)$ & 15 & 22.72 \\
\hline Poor $(<70)$ & 7 & 10.6 \\
\hline
\end{tabular}


Fig. 2: Cemented bipolar hemiarthopalsty

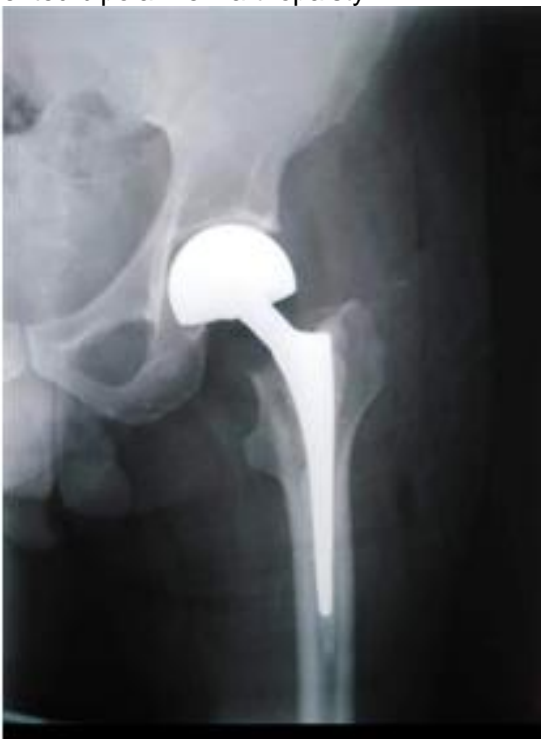

\section{DISCUSSION}

$\mathrm{Ali}^{20}$ has evaluated recently the functional outcome of physiologically active elderly 50 cases, with men age of $63.36 \pm 7.27$ years, in his conclusion he said that functional level of most cases is restored to pre injury level \& found this implant successful in $74 \%$ of cases.

Sikorski ${ }^{21}$ in his study he found that mobility status of patients compromised after Thompson hemiarthroplsty by anterior approach as compare to posterior approach; the latter resulted the better functional outcome. We also done all cases with posterior Moore approach \& observed better functional outcome.

Sierra ${ }^{22}$ observed $1.76 \%$ dislocations in 1812 cases after bipolar hemiarthroplsty in 26 year period, they opened hips through anterolateral approach in $79 \%$ of cases, but in his conclusion he did not found any relationship of dislocation with any of approach, and most cases presented within 6 months of surgery and they reduced by closed method in one third of cases. While in our study we operated all cases through posterior Moore approach \& observed the $4.54 \%$ dislocation. While in another study dislocation was higher with posterior approach 9.0\% (149 in 1656) compared to the direct lateral approach was $3.3 \%$ (41 in 2150). ${ }^{23}$

Frihagen ${ }^{24}$ compared osteosynthesis to replacement arthroplasty in cases above 60 year of age for functional outcome by Harris hip score \& observed better functional status operated by hemiarthroplsty compared to internal fixation group. Parker ${ }^{25}$ in his study reported average operative time of $46.4 \pm 11.8$ with 223 cases of hemiarthroplsty, while we documented $55.67 \pm 9.9$ minutes in 66 cases. Tol ${ }^{26}$ in his 12 year follow up of 252 cases of Partial Hip Arthroplasty and Total Hip Arthroplasty in elderly sample of 252 cases, they found no significant difference in reference to functional status, morbidity and mortality between both groups. Chhabra ${ }^{27}$ in his study of 30 cases reported; $60 \%$ females $40 \%$ males, $46.66 \%$ midcervical $36.66 \%$ subcpital FNF fractures, with satisfactory functional outcome in most of cases. In our study $77 \%$ were midcervical cases\& $60 \%$ females. Somashekar ${ }^{28}$ documented the average Harris hip score of $86.18 \pm 12.18$ in $\mathrm{n}=20$. We also witnessed comparable functional outcome with satisfactory Harris hip score in most of cases.

Robertson ${ }^{18}$ in his study of different Meta-analyses and Cochrane reviews summarizes that long term follow up of unipolar and bipolar hemirthroplasty make no difference in any sort of outcome, although bipolar is expensive so it should not be preferred over unipolar component, they reported more dislocation ratio with posterior approach compare to other approaches, cemented component was related with better functional outcome.

\section{CONCLUSION}

Bipolar implant is safe, effective, reliable, stable and cost effective implant for intracpsular fracture of femoral neck [FNF] in elderly populace. The $66.66 \%$ of patients have excellent to good Harris hip score in follow up duration of $18.45 \pm 7.63$ months.

\section{REFERENCES}

1. Veronese N, Maggi S. Epidemiology and social costs of hip fracture. Injury 2018;49(8):1458-60.

2. Al-Ani AN, Neander G, Samuelsson B, Blomfeldt R, Ekström W, Hedström M. Risk factors for osteoporosis are common in young and middle-aged patients with femoral neck fractures regardless of trauma mechanism. Acta Orthopaedica 2013;84(1):54-9.

3. Burge Rs, Dawson-Hughes B, Solomon DH, Wong JB, King A, Tosteson A. Incidence and economic burden of osteoporosis-related fractures in the United States, 20052025. J Bone Mineral Res 2007;22(3):465-75.

4. Pauyo T, Drager J, Albers A, Harvey EJ. Management of femoral neck fractures in the young patient: A critical analysis review. World J Orthop 2014;5(3):204.

5. Kanaan M, Shahnawaz S, Kumar R, Ahmad A, Bhatti A. Epidemiology of Orthopedic Trauma in The Geriatric Population of Karachi, Pakistan. J Pak Orthop Assoc 2017;29(2):48-53.

6. Smith T, Pelpola K, Ball M, Ong A, Myint PK. Pre-operative indicators for mortality following hip fracture surgery: a systematic review and meta-analysis. Age Ageing 2014;43(4):464-71.

7. Parker MJ, Gurusamy KS. Internal fixation versus arthroplasty for intracapsular proximal femoral fractures in adults. Cochrane Database Sys Rev 2006(4).

8. World Health Organization. Health Situation in the South-East Asia Region, 2001-2007. WHO Regional Office for South-East Asia; 2008

9. Speed K. The classic the unsolved fracture. Clin Orthop Relat Res 1980;152:3-9.

10. Tseng FJ, Chia WT, Pan RY, Lin LC, Shen $\mathrm{HC}$, Wang $\mathrm{CH}$, Shyu JF, Weng CF. Comparison of arthroplasty vs. osteosynthesis for displaced femoral neck fractures: a metaanalysis. J Orthop Surg Res 2017;12(1):1-5.

11. Garden RS. Low-angle fixation in fractures of the femoral neck. J Bone Joint Surg [Br] 1961;43(4):647-63.

12. Florschutz AV, Langford JR, Haidukewych GJ, Koval KJ. Femoral neck fractures: current management. J Orthop Trauma 2015; 29(3):121-9.

13. van der Sijp MP, van Delft D, Krijnen $P$, Niggebrugge $A H$, Schipper IB. Surgical approaches and hemiarthroplasty outcomes for femoral neck fractures: a meta-analysis. J Arthroplasty 2018;33(5):1617-27. 
14. Jia Z, Ding F, Wu Y, Li W, Li H, Wang D, He Q, Ruan D. Unipolar versus bipolar hemiarthroplasty for displaced femoral neck fractures: a systematic review and meta-analysis of randomized controlled trials. J Orthop Surg Res 2015;10(1):18.

15. Veldman HD, Heyligers IC, Grimm B, Boymans TA. Cemented versus cementless hemiarthroplasty for a displaced fracture of the femoral neck: a systematic review and meta-analysis of current generation hip stems. Bone Joint J 2017;99(4):421-31.

16. Fitch DA, Sedacki K, Yang Y. Mid-to long-term outcomes of a medial-pivot system for primary total knee replacement: a systematic review and meta-analysis. Bone $J$ Res 2014;3(10):297-304 .

17. Leighton RK, Schmidt AH, Collier P, Trask K. Advances in the treatment of intracapsular hip fractures in the elderly. Injury 2007; 38 Suppl 3: S24-34.

18. Robertson GA, Wood AM. Hip hemi-arthroplasty for neck of femur fracture: What is the current evidence?. World J Orthop 2018 18;9(11):235.

19. Harris WH. Traumatic arthritis of the hip after dislocation and acetabular fractures: treatment by mold arthroplasty: an endresult study using a new method of result evaluation. J Bone Joint Surg Am 1969;51(4):737-55.

20. Ali S, Iqbal MF, Aziz S, et al. Functional outcome of bipolar hemiarthroplasty. PJMHS 2021; 15(1):

21. Sikorski JM, Barrington R. Internal fixation versus hemiarthroplasty for the displaced subcapital fracture of the femur: a prospective randomised study. J Bone Joint Surgery $\mathrm{Br} 1981 ; 63(3): 357-61$.
22. Sierra RJ, Schleck CD, Cabanela ME. Dislocation of bipolar hemiarthroplasty: rate, contributing factors, and outcome. Clin Orthop Relat Res 2006;442:230-8.

23. Unwin AJ, Thomas M. Dislocation after hemiarthroplasty of the hip: a comparison of the dislocation rate after posterior and lateral approaches to the hip. Ann Royal Coll Surg Eng 1994;76(5):327.

24. Frihagen F, Nordsletten L, Madsen JE. Hemiarthroplasty or internal fixation for intracapsular displaced femoral neck fractures: randomised controlled trial. BMJ 2007;335(7632):1251-4.

25. Parker MJ, Khan RJ, Crawford J, Pryor GA. Hemiarthroplasty versus internal fixation for displaced intracapsular hip fractures in the elderly: a randomised trial of 455 patients. J Bone Joint Surg $\mathrm{Br}$ 2002;84(8):1150-5.

26. Tol MC, Van Den Bekerom MP, Sierevelt IN, Hilverdink EF, Raaymakers EL, Goslings JC. Hemiarthroplasty or total hip arthroplasty for the treatment of a displaced intracapsular fracture in active elderly patients: 12-year follow-up of randomised trial. Bone Joint J 2017; 99(2):250-4.

27. Chhabra SS, Gupta U, Gupta S. Functional outcome of bipolar hemiarthroplasty in fracture neck of femur. Int $\mathrm{J}$ Orthop 2020;6(3):32-6.

28. Somashekar SV, Murthy JS. Treatment of femoral neck fractures: unipolar versus bipolar hemiarthroplasty. Malaysian Orthop J 2013;7(2):6. 